\title{
Pengusahaan Mawar Potong di di Mayungan, Bali
}

\author{
Cut Rose Production at di Mayungan, Bali
}

\section{Wahyu Arif Sudarsono, Dewi Sukma*, dan Juang Gema Kartika}

\author{
Departemen Agronomi dan Hortikultura,Fakultas Pertanian, Institut Pertanian Bogor (Bogor \\ Agricultural University), Jl. Meranti, Kampus IPB Darmaga, Bogor 16680, Indonesia Telp. \\ \& Faks. 62-251-8629353 e-mail agronipb@indo.net.id \\ *Penulis korespondensi: dsukma70@yahoo.com
}

Disetujui tanggal 14 November 2016/ Published online 8 Desember 2016

\begin{abstract}
Rose is a popular lead of cutflower in Indonesia. This plant requires intensive management in all of part of production, started from media preparation to post harvest handling. This research are to improve knowlegde, skill, and abilities the writer in cut rose production. The internship has February until June 2009 in Mayungan, Bali. Primary and secondary data caracter of quantitative such as growth, stem length, and production was analyzed using quantitative analysis using the average and standard deviation, while qualitative data were analyzed using analysis of post-harvest deskriptif. Post-harvest include the collection of flowers that have been cut, transportation to the packing house, sorting and selection of quality, binding, packaging, storage, and transport.
\end{abstract}

Keyword: ornamental plant, post harvest, stem length,

\begin{abstract}
ABSTRAK
Mawar merupakan salah satu produk tanaman hias unggulan Indonesia. Tanaman ini memerlukan pengelolaan yang intensif dari persiapan bahan tanam hingga pengelolaan pasca panen. Kegiatan magang bertujuan untuk meningkatkan pengetahuan, kemampuan, dan keterampilan mahasiswa dalam budidaya mawar potong. Kegiatan penelitian dilaksanakan pada bulan Februari hingga Juni 2009 di Mayungan, Bali. Data primer dan sekunder yang bersifat kuantitatif (numeric) seperti pertumbuhan, panjang tangkai, dan hasil produksi dianalisis dengan menggunakan analisis kuantitatif menggunakan rata-rata dan standar deviasi, sedangkan data yang bersifat kualitatif dianalisis dengan menggunakan analisis deskriptif. Penanganan pasca panen yang meliputi pengumpulan bunga yang telah dipotong, pengangkutan ke packing house, sortasi dan seleksi kualitas, pengikatan, pembungkusan, penyimpanan, dan pengangkutan.
\end{abstract}

Kata kunci: panjang tangkai, pasca panen, tanaman hias 


\section{PENDAHULUAN}

Peluang pengembangan usaha agribisnis tanaman hias maupun bunga potong di Indonesia masih terbuka lebar. Di masa mendatang diperkirakan pertumbuhan tingkat permintaan bunga potong di Indonesia akan meningkat $10 \%$ setiap tahunnya (www.tanindo.com). Salah satu jenis bunga potong yang telah dikembangkan secara luas adalah mawar. Indonesia berpeluang besar dalam mengembangkan agribisnis dari komoditas ini, baik untuk memenuhi permintaan dalam maupun luar negeri. Menurut Lingga (2008) pasar mawar dunia meliputi bunga potong, tanaman hias pot, tanaman penghias taman (landscape plant), air mawar (rose water), parfum, herbal, dan produk kosmetik berbasis aroma mawar. Selain itu mawar dapat digunakan sebagai bunga tabur dan tanaman obat. Berdasarkan data Badan Pusat Statistik tahun 2009 luas panen mawar potong di Indonesia pada tahun 2008 seluas $916 \quad 093 \quad \mathrm{~m} 2$ dengan produktivitas sebesar 10.5 tangkai per $\mathrm{m} 2$. Produksi mawar potong tahun 1997-2008 cukup berfluktuasi. Produksi mawar tahun 1997 mencapai 123439324 tangkai dan tahun 1998 turun menjadi 63291838 tangkai. Produksi turun hingga mencapai 39131608 tangkai pada tahun 2008. Meskipun demikian, mawar tetap menjadi tanaman unggulan nasional disamping krisan yang memiliki produksi pada tahun 2007 dan 2008 masing-masing sebesar 66979260 tangkai dan 99 158942 tangkai.

Budidaya mawar potong tidak mudah, sehingga diperlukan suatu teknik budidaya yang tepat dari persiapan media tanam hingga penanganan pasca panen. Tanaman mawar memerlukan banyak unsur hara untuk pertumbuhan dan rentan terhadap serangan hama dan penyakit tanaman. Jika tidak dikelola dengan baik, maka mawar tidak akan memiliki kualitas yang maksimal. Selain tindakan budidaya, diperlukan upaya dan kemauan dari berbagai kalangan baik institusi pemerintahan ataupun elemen masyarakat untuk dapat berpartisipasi aktif dalam usaha pengembangan agribisnis tanaman hias, tanpa terkecuali tanaman mawar. Peningkatan produksi mawar dipengaruhi oleh tindakan budidaya. Pelaksanaan budidaya yang baik dapat meningkatkan kuantitas dan kualitas produksi yang akan meningkatkan animo konsumen untuk membeli. Effendie (1994) menyatakan konsumen pada umumnya menyukai bentuk satuan atau ikatan bunga. Bentuk rangkaian dan lainnya lebih sedikit diminati konsumen. Oleh karena itu, selain pemahaman budidaya mawar, diperlukan juga pengetahuan mengenai kondisi pasar seperti selera konsumen.

Kegiatan penelitian bertujuan untuk meningkatkan pengetahuan, kemampuan, dan keterampilan dalam budidaya mawar, pengelolaan produksi, dan aspek manajerial kebun. Sebagai sumbangsih mahasiswa sebagai insan pendidikan terhadap pengembangan tanaman hias nasional.

\section{BAHAN DAN METODE}

Penelitian dilaksanakan di Mayungan, Bali. Kegiatan ini berlangsung pada bulan Februari hingga Juni 2009.

Data yang dikumpulkan berupa data primer dan data sekunder. Data primer merupakan data hasil pengamatan secara langsung di lapangan, sedangkan data sekunder merupakan data yang diperoleh dari kantor perusahaan ataupun instansi terkait. Data primer yang dikumpulkan meliputi pertumbuhan panjang tangkai mawar setelah tagging maupun setelah tanam, umur panen mawar, karakteristik varietas mawar, serta pengamatan teknis budidaya yang dilakukan seperti pemupukan, pengairan, dan pengendalian hama. Data sekunder yang dikumpulkan meliputi data hasil produksi, ketenagakerjaan, iklim, dan data bibit. Data yang telah dikumpulkan digabung, sehingga menjadi laporan. Metode yang digunakan dalam pengumpulan data primer dan data sekunder adalah wawancara dengan staf dan pekerja, melakukan kegiatan budidaya secara langsung, pengumpulan data perusahaan, pengamatan pertumbuhan mawar, dan melakukan studi pustaka.

Data yang telah dikumpulkan dianalisis secara deskriptif maupun kuantitatif. Data primer dan sekunder yang bersifat kuantitatif (numeric) seperti pertumbuhan panjang tangkai dan hasil produksi dianalisis dengan menggunakan analisis kuantitatif menggunakan rata-rata dan standar deviasi, sedangkan data yang bersifat kualitatif dianalisis dengan menggunakan analisis deskriptif.

\section{HASIL DAN PEMBAHASAN}

\section{Pemeliharaan Sebelum Panen}

Persiapan tanam. Mawar dibudidayakan merupakan mawar untuk produksi bunga potong dan mawar spa. Bahan tanam mawar didatangkan dari daerah lain atau bibit impor berupa bibit hasil sambungan (grafting) dan stek berakar (rooted cutting). Mawar oleh perusahaan dibedakan menjadi beberapa golongan berdasarkan asal bibit 
yaitu mawar Lembang, mawar Malang, dan mawar Jepang. Media tanam bibit mawar Malang dan Lembang adalah sekam, sedangkan pada mawar Jepang berupa rockwool.

Kompos ditambahkan sebagai media tanaman mawar dan tanaman lain yang dibudidayakan. Bahan yang digunakan dalam pengomposan adalah cocopeat, pupuk kandang gajah (elephant manure), kompos daun, dan sekam dengan perbandingan 2:2:2:1. Masingmasing bahan tersebut memiliki fungsi yang berbeda-beda. Cocopeat memiliki fungsi memegang air, sedangkan kotoran gajah, sekam, dan kompos daun digunakan untuk mendukung aerasi dan porositas media. Media tanam yang digunakan berbeda-beda antar rumah plastik dan kebun karena masih dalam tahap penyempurnaan. Media tanam yang digunakan di Kebun I hanya berupa tanah dan pupuk kandang. Menurut Durkin
(1992) komposisi kompos terdiri dari bahan yang memiliki berbagai fungsi penunjang seperti pupuk kandang untuk memegang air dan sekam untuk aerasi media tanam. Untuk meningkatkan aerasi tanah setelah dilakukan irigasi, tanah dapat dicampurkan dengan pasir kasar, jerami kering, scoria, dan bahan organik lainnya seperti sekam, tatal kayu, serbuk gergaji, dan kotoran ternak.

Penanaman dilakukan bergilir pada setiap Green House yang dimulai pada GH 1 dibulan Februari. Varietas mawar yang ditanam juga berbeda-beda. GH 1 menanam varietas Black Magic, Red Baron, dan Sereal sedangkan GH 2 menanam varietas Tuscany, Universe, Avalanche, Candle, Small Wood, Grand Gala (Tabel 1). Varietas mawar Lembang memiliki rata-rata dibandingkan dengan varietas mawar Malang yaitu Black Magic dan Sereal (Tabel 2).

Tabel 1. Data populasi awal tanam mawar

\begin{tabular}{ccccc}
\hline $\begin{array}{c}\text { Rumah } \\
\text { plastik }\end{array}$ & Tanggal tanam & $\begin{array}{c}\text { Populasi awal } \\
\text { tanam }\end{array}$ & $\begin{array}{c}\text { Populasi per } \\
\text { 11 Maret 2009 }\end{array}$ & Varietas \\
\hline GH I/1 & 20 Feb 08 & 4934 & $*$ & BMA, RBA, SRA \\
GH I/2 & 20 Feb 08 & 5589 & $*$ & BMA, RBA, SRA \\
GH I/3 & 20 Feb 08 & 1979 & $*$ & BMA, RBA, SRA \\
GH I/4 & 20 Feb 08 & 2901 & $*$ & BMA, RBA, SRA \\
GH I/6 & 20 Feb 08 & 3609 & $*$ & BMA, RBA, SRA \\
GH I/7 & 20 Feb 08 & 3511 & $*$ & BMA, RBA, SRA \\
GH I/8 & 20 Feb 08 & 2584 & $*$ & BMA, RBA, SRA \\
GH I/9 & 20 Feb 08 & 2098 & $*$ & BMA, RBA, SRA \\
GH I/10 & 20 Feb 08 & 1789 & $*$ & BMA, RBA, SRA \\
GH I/11 & 1 Maret 09 & 4974 & 5094 & SWO, CDL \\
GH II/1 & 10 Apr 08 & 4569 & 4160 & GGA, UNI, TUS, AVA \\
GH II/2 & 20 Apr 08 & 4042 & 3588 & GGA, UNI, TUS, AVA \\
GH II/3 & 27 Apr 08 & 4628 & 3545 & GGA, UNI, TUS, AVA \\
GH II/7 & 6 Juni 08 & 4852 & 4130 & GGA, UNI, TUS, AVA \\
GH II/8 & 9 Juni 08 & 3423 & 2909 & GGA, UNI, TUS, AVA, MGW, \\
GH II/9 & 11 Juni 08 & 9359 & 8231 & MGP, LNY, STN \\
\hline
\end{tabular}

Keterangan: BMA : ‘Black Magic, ' TOS: ‘Tuscany', UNI: ‘Universe', RBA : ‘Red Baron', AVA : ‘Avalanche', CDL :

'Candle', SRA: 'Sereal', SWO: 'Small Wood', GGA : 'Grand Gala, *:Tidak dilakukan penghitungan karena tanaman akan dibongkar dan diganti dengan tanaman baru

Tabel 2. Pertumbuhan panjang tangkai mawar Lembang dan Malang

\begin{tabular}{|c|c|c|c|c|c|c|}
\hline \multirow{2}{*}{ Varietas } & \multicolumn{6}{|c|}{ MST } \\
\hline & 1 & 2 & 3 & 4 & 5 & 6 \\
\hline Mawar Lembang & & \multicolumn{5}{|c|}{ 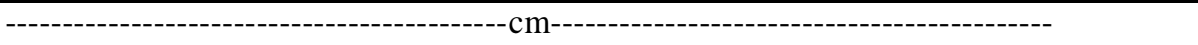 } \\
\hline Avalanche & $2.33 \pm 1.22$ & $14.72 \pm 9.38$ & $35.21 \pm 14.23$ & $40.59 \pm 13.99$ & $39.29 \pm 12.67$ & \\
\hline Universe & $1.33 \pm 0.52$ & $7.91 \pm 7.36$ & $24.64 \pm 14.28$ & $39.77 \pm 15.71$ & $50.50 \pm 17.92$ & $53.96 \pm 20.60$ \\
\hline Tuscany & $0.51 \pm 0.49$ & $5.58 \pm 3.43$ & $24.92 \pm 12.76$ & $45.94 \pm 14.82$ & $51.32 \pm 9.36$ & $53.90 \pm 9.88$ \\
\hline Grand Gala & $1.13 \pm 0.33$ & $5.67 \pm 7.02$ & $15.67 \pm 14.41$ & $41.43 \pm 14.02$ & $50.51 \pm 25.34$ & $57.40 \pm 25.42$ \\
\hline \multicolumn{7}{|l|}{ Mawar Malang } \\
\hline Black Magic & $0.21 \pm 0.34$ & $2.41 \pm 3.23$ & $11.58 \pm 11.39$ & $21.64 \pm 15.31$ & $26.02 \pm 22.23$ & $20.57 \pm 22.24$ \\
\hline Sereal & $1.11 \pm 1.11$ & $4.14 \pm 6.84$ & $86.00 \pm 7.16$ & $8.69 \pm 7.56$ & $8.45 \pm 6.85$ & $10.43 \pm 9.69$ \\
\hline
\end{tabular}

Keterangan: MST : Minggu Setelah Tagging, Panjang tangkai : rata-rata \pm standar deviasi

Pengairan (Irigasi). Fasilitas irigasi di terdiri dari empat buah generator. Dua generator berfungsi untuk menyedot air dari sumber air dan dua generator lainnya digunakan untuk mengalirkan air menuju rumah plastik, masingmasing satu generator untuk satu kebun. Sumber 
air yang digunakan berjarak kurang lebih 300 meter dari kebun dengan waktu tempuh 15 menit dengan berjalan kaki. Air yang telah disedot oleh generator ditampung di dalam bunker air.

Pada tahun awal produksi (tahun 20082009), menggunakan sistem irigasi manual (manual spraying) dengan menggunakan selang. Sistem ini tidak efisien karena membutuhkan banyak tenaga kerja dan waktu yang lebih lama. Oleh karena itu sistem irigasi yang dipergunakan sekarang (tahun 2009) adalah irigasi dengan menggunakan sprinkler. Selain menghemat waktu, sistem ini lebih hemat dalam penggunaan air. Setiap planter terdapat dua buah pipa PVC berdiameter 0.5 inch dengan nozzle sprinkler masing-masing berjarak 0.5 meter. Sprinkler berhadapan satu sama lain dengan kombinasi zigzag. Waktu yang diperlukan untuk penyiraman setiap planter adalah lima menit.

Sprinkler dimatikan jika kondisi media tanam sudah cukup basah atau belum yang dilakukan secara visual oleh karyawan rumah plastik. Jika masih kurang, maka irigasi terus dilakukan hingga media tanam benar-benar basah. Selain pendugaan irigasi secara visual, digunakan juga alat bantu $\mathrm{pF}$ meter dengan merk Daiki $\mathrm{pF}$ meter O2. Pendugaan secara visual lebih banyak digunakan sebagai pertimbangan dalam pelaksanaan irigasi dibandingkan dengan penggunaan alat $\mathrm{pF}$ meter.

Reid (2008) menyatakan bahwa di Australia terdapat dua sistem pengairan yang dilakukan pada mawar yaitu micro sprinkler dan tricle irrigation. Micro sprinkler dapat memberikan kelembaban pada permukaan tanah karena penyiraman dilakukan dengan proporsi yang sama. Tricle irrigation merupakan teknik irigasi dengan menggunakan pipa untuk mengalirkan air ke media tanam.

\section{Pemangkasan (pruning). Pruning} merupakan kegiatan pemeliharaan rutin yang dilakukan. Pruning hanya dilakukan pada mawar Malang saja karena diharapkan dalam satu tanaman dapat menghasilkan banyak bunga yang dapat dipanen untuk tujuan spa. Pruning dilakukan pada tanaman yang sudah terlalu tinggi, tanaman yang sudah tidak produktif, tanaman yang sudah tidak mempunyai bentuk yang baik, dan tanaman yang terserang hama dan penyakit. Dalam pelaksanaannya pruning dilakukan sesuai dengan kondisi tanaman yang ada. Jika memungkinkan dilakukan hard pruning (penggundulan), maka hard pruning dilakukan. Jenis pruning yang paling banyak dilakukan adalah moderate pruning (pemangkasan sedang) untuk membentuk tajuk tanaman. Pruning dilakukan dengan menggunakan gunting tanaman yang tajam dan steril. Sterilisasi dilakukan dengan cara membakar gunting dengan cairan alkohol. Setelah dipotong, tangkai atau batang tanaman tersebut dipotong menjadi bagian yang lebih kecil untuk memudahkan proses pembuangan. Beberapa hal yang perlu diperhatikan dalam pelaksanaan pemangkasan mawar menurut Rukmana (1994) adalah bidang potong pangkasan harus memiliki kemiringan

$\mathrm{O}$

45 , arah pangkasan sejajar dengan arah mata tunas, dan jarak bidang pemangkasan sekitar 4-6 $\mathrm{mm}$ dari mata tunas.

Pengaturan $\mathrm{pH}$ dan EC. Pengukuran $\mathrm{pH}$ dan EC (Electric Conductivity) telah dilakukan setiap bulannya. EC menunjukkan jumlah total garam terurai (TDS/Total Dissolved Salts) atau jumlah total ion yang terurai di air (www.lakeaccess.com). Jika nilai EC media tanam rendah, maka perlu dilakukan pemupukan untuk meningkatkan kadar ion dan sebaliknya jika nilai EC tinggi, maka diperlukan penyiraman air karena mengindikasikan kadar ion yang tinggi. Nilai EC optimal untuk media tanam mawar adalah berkisar antara $1.0-1.5 \mathrm{mS} / \mathrm{cm}$ dan $\mathrm{pH}$ berkisar antara 6-8. Alat yang digunakan untuk mengukur $\mathrm{pH}$ adalah $\mathrm{pH}$ meter dengan merk Twin $\mathrm{pH}$ Waterproof, sedangkan alat untuk mengukur EC adalah EC meter dengan merk Twin Cond Conductivity yang merupakan produk dari Horiba, Ltd., Jepang.

Menurut Rukmana (1994) jenis dan dosis pupuk yang dianjurkan untuk tanaman mawar adalah pupuk NPK (5-10-5) sebanyak 5 gram per tanaman. Bila pertumbuhan tunas-tunasnya lambat dapat dipupuk NPK (10-10-5), sedangkan bila tangkai-tangkainya lemah dipupuk NPK (5-15-5). Masalah lain dalam pengukuran $\mathrm{pH}$ dan EC adalah tingkat keakuratan alat yang masih diragukan.

Pengaturan ventilasi. Ventilasi diperlukan untuk menjaga kelancaran sirkulasi udara dalam rumah plastik. Sirkulasi udara yang baik berguna bagi tindakan pengendalian hama dan penyakit tanaman. Semua rumah plastik memiliki sistem ventilasi yang cukup baik karena memiliki tirai (screen) yang dapat dibuka tutup dan atap yang memiliki lubang ventilasi. Jika turun hujan tirai ditutup untuk mencegah masuknya air. Masuknya air hujan dapat meningkatkan kelembaban relatif yang dapat memicu timbulnya penyakit Downey Mildew. Untuk mencegah serangan penyakit ini, pada dinding rumah plastik ditambahkan plastik UV yang dapat digunakan pada malam hari dan jika turun hujan. Selain itu, pada beberapa rumah 
plastik telah dipasang kipas angin (fan).

Pengendalian Hama dan Penyakit Tanaman. Mawar merupakan tanaman yang sangat rentan terhadap serangan hama dan penyakit. Jika budidaya mawar yang dilakukan berorientasi komersial, maka pengendalian hama dan penyakit harus menjadi prioritas utama untuk menghasilkan tanaman yang berkualitas baik. Aplikasi pestisida dilakukan setiap minggu untuk satu jenis pestisida dengan melihat tingkat serangan hama dan penyakit. Tingkat serangan hama dan penyakit tanaman akan menentukan jumlah konsentrasi pestisida yang digunakan. Jika tingkat serangan hama dan penyakit tanaman tinggi, maka konsentrasi yang digunakan akan ditambah. Hama utama yang menyerang tanaman mawar adalah Spider Mites dan Aphids. Penyakit utama yang menyerang adalah Downey Mildew.

Varietas mawar yang dimiliki, memiliki lama membuka mahkota bunga yang berbeda. Dari empat varietas mawar utama yang ada yaitu 'Grand Gala', 'Universe', 'Tuscany', dan 'Avalanche', varietas yang paling cepat membuka mahkotanya adalah 'Grand Gala' dan 'Avalanche'. Keempat varietas utama tersebut juga memiliki diameter panen bunga yang bervariasi (Tabel 3).

Tabel 3. Diameter bunga siap panen tiap varietas mawar

\begin{tabular}{ccc}
\hline Varietas & Diameter $(\mathrm{cm})$ & Ukuran Bunga \\
\hline Avalanche & $4-5$ & Besar \\
Universe & $4-5$ & Besar \\
Tuscany & $4-5$ & Besar \\
Grand Gala & $2.5-3.5$ & Medium \\
\hline
\end{tabular}

\section{Pasca Panen}

Penanganan pasca panen yang dilakukan meliputi pengumpulan bunga yang telah dipotong, pengangkutan ke packing house, sortasi dan seleksi kualitas, pengikatan dan pembungkusan, penyimpanan, dan pengangkutan. Menurut Aisyah (2008) faktor-faktor yang mempengaruhi kualitas pasca panen tanaman hias antara lain tingkat mekar bunga, suplai hara, suhu, suplai air, etilen, gerakan pertumbuhan, kerusakan mekanis, dan penyakit tanaman. Segera setelah panen dilakukan pengawetan mawar potong, baik dengan merendam dalam air panas atau mencampur kalium permanganat ke dalam air bersih dengan konsentrasi $0.3 \%$ (3 gram dalam 10 liter air) (Lingga, 2008).

\section{Pengumpulan Bunga yang Telah} Dipotong. Bunga yang telah dipotong segera dimasukkan ke dalam ember yang berisi air yang disesuaikan dengan kebutuhan. Ember harus diletakkan ditempat yang teduh, terlindung dari panas matahari, dan terhindar dari percikan air atau kotoran lainnya. Hal ini dilakukan agar hasil panen terhindar dari layu dan kerusakan lainnya yang menyebabkan kualitas tanaman menurun.

Pengangkutan ke Packing House. Hasil panen yang telah dikumpulkan diangkut ke packing house untuk selanjutnya dilakukan sortasi dan seleksi. Pengangkutan dilakukan secara hatihati untuk mencegah terjadinya kerusakan mekanis seperti patah dan memar. Mawar yang telah dipanen diangkut menuju packing house dengan menggunakan ember yang berisi air. Karena jarak kebun produksi dengan packing house dekat, kegiatan sortasi dilakukan segera setelah hasil panen sampai.

Sortasi dan Seleksi Kualitas. Bunga yang telah berada di packing house diperiksa dan diteliti untuk melihat keadaan bunga, tingkat kemekaran bunga, keadaan tangkai bunga yang meliputi panjang pendek, lurus bengkok, besar kecilnya, dan tegar lemas (vigor) bunga, serta kebersihan daunnya (Supari, 1999). Bunga yang berkualitas buruk seperti berlubang karena serangan ulat, layu, dan kerusakan lainnya tidak dimasukkan dalam penanganan pasca panen. Selama sortasi dilakukan juga penghilangan duri dan daun pada tangkai bagian bawah. Mawar yang telah disortasi dan diseleksi dikumpulkan tiap varietas dan direndam air dalam ember. Tempat penelitian belum menerapkan sistem grading panen mawar secara baku dan baru terbatas pada panjang tangkai. Grading dilakukan pada meja yang telah diberikan ukuran dari $50 \mathrm{~cm}$ hingga $80 \mathrm{~cm}$.

Pengikatan dan Pembungkusan. Pengikatan mawar dilakukan setelah kegiatan sortasi dan seleksi selesai. Pengikatan mawar didasarkan pada beberapa kriteria yaitu dalam satu ikat terdiri dari mawar yang memiliki tingkat mekar, varietas, panjang batang, dan ukuran kuntum bunga yang sama. Setiap ikat mawar terdiri dari 20 tangkai. Setelah diikat mawar dibungkus dengan menggunakan kertas karton. Pembungkusan ini bertujuan untuk menjaga agar bunga tidak mengalami kerusakan 
selama pengiriman. Karton lebih baik digunakan daripada plastik karena mampu menahan goncangan dan gesekan yang terjadi.

Penyimpanan. Penyimpanan dilakukan jika hasil panen tidak dikirim langsung ke pelanggan. Berdasarkan waktu penyimpanan mawar di Kebun Bali Rose tergolong penyimpanan sementara, sedangkan berdasarkan perlakuan tergolong dalam penyimpanan basah.

Selama penyimpanan sementara di kebun digunakan campuran air dan bahan pengawet Chrysal dengan konsentrasi 2 cc/liter air pada suhu ruang. Perendaman tangkai bunga dalam larutan pengawet bertujuan untuk mempertahankan kualitas dan memperpanjang vase life bunga karena larutan tersebut mengandung zat yang mampu menghambat pembentukan senyawa etilen pada tanaman hasil panen, sehingga proses senesen akan terhambat. Penggunaan suhu ruang dalam penyimpanan mawar disebabkan karena tidak adanya fasilitas ruang pendingin (cold storage) di kebun dan hanya tersedia di kantor pusat. Di dalam cold storage mawar disimpan pada suhu $14-15^{\circ} \mathrm{C}$ sebelum dikirimkan ke pelanggan.

Pengiriman. Pengiriman hasil panen merupakan kegiatan pasca panen yang terakhir dilakukan. Pengiriman dilakukan dengan menggunakan mobil boks berpendingin udara. Suhu dalam mobil boks diatur pada kisaran $15^{\circ} \mathrm{C}$. Di dalam mobil boks mawar diatur, sehingga tidak mengalami kerusakan mekanis. Kuntum bunga dan tangkai masing-masing diletakkan pada arah yang sama. Selama pengiriman berlangsung mawar yang ada di dalam mobil boks tidak dimasukkan dalam larutan pengawet. Setelah sampai di tempat tujuan sebaiknya ujung tangkai mawar dipotong, kemudian dimasukkan dalam ember yang berisi air hangat dan disimpan di ruang cold storage. Jumlah tangkai mawar yang dipanen dan dikirim pada bulan Mei 2009 seperti terlihat pada Tabel 4.

Dari data pada Tabel 6 diketahui bahwa mawar yang dikirim pada bulan Mei 2009 lebih rendah 203 tangkai $(2.91 \%)$ dari jumlah mawar yang dipanen. Nilai ini tergolong rendah, artinya jika terdapat 100 tangkai mawar yang dipanen, jumlah tangkai yang hilang atau rusak selama proses pasca panen hanya berjumlah tiga tangkai. Pada beberapa pelaksanaan panen jumlah mawar yang dikirim lebih banyak dari mawar yang dipanen. Hal ini disebabkan adanya tambahan panen mawar yang tidak dicatat dan adanya sisa panen sebelumnya yang belum dikirim.

Tabel 4. Jumlah tangkai mawar yang dipanen dan dikirim di kebun pada bulan Mei 2009

\begin{tabular}{lcrr}
\hline \multicolumn{1}{c}{ Panen ke- } & Jumlah panen & Jumlah pengiriman & \% kehilangan per panen \\
\hline I (2-4 Mei 2009) & 1140 & 1140 & 0.00 \\
II (9-11 Mei 2009) & 682 & 680 & 0.29 \\
III (12-13 Mei 2009) & 440 & 440 & 0.00 \\
IV (14-15 Mei 2009) & 490 & 490 & 0.00 \\
V (16-18 Mei 2009) & 518 & 410 & 20.85 \\
VI (19-20 Mei 2009) & 563 & 510 & 9.41 \\
VIII (21-22 Mei 2009) & 503 & 495 & 1.59 \\
IX (23-25 Mei 2009) & 885 & 885 & 0.00 \\
X (26-27 Mei 2009) & 802 & 800 & 0.25 \\
XI (28-29 Mei 2009) & 950 & 920 & 3.16 \\
\hline Jumlah & 6973 & 6770 & - \\
\hline
\end{tabular}

\section{KESIMPULAN}

Pelaksanaan tahapan-tahapan budidaya telah dilaksanakan secara sistematis dengan adanya pembagian kerja (job description). Selain itu, juga didukung oleh tenaga ahli yang kompeten di bidang mawar. Meskipun demikian, terdapat beberapa permasalahan yang harus ditindak lanjuti seperti manajemen dan organisasi kebun, persiapan media tanam, pelaksanaan perbanyakan tanaman, pemupukan, pelaksanaan sistem grading, serta pengendalian hama dan penyakit tanaman.

\section{DAFTAR PUSTAKA}

Lingga, L. 2008. Mawar. PT. Gramedia. Jakarta. 126 hal.

Aisyah, S. I. 2008. Sistem Penanganan Pasca Panen pada Tanaman Hias. Tanaman Hias dan Bunga. Departemen Agronomi dan Hortikultura. Fakultas Pertanian. Institut Pertanian Bogor.

Anonim. 2008. Agribisnis bunga potong anggrek. http://www.tanindo.com. $\quad[13$ Desember 2008] 
Anonim. 2009. Electrical conductivity:measuring salts in water. http://www.lakeaccess.com. [10 Agustus 2009].

Durkin, D. J. 1992. Introduction to Floriculture Second Edition. In Larson, Roy A. $(E d s)$. Academic Press, Inc. San Diego, California.
Effendie, K. 1994. Tata niaga dan perilaku konsumen bunga potong. Pusat Penelitian dan Pengembangan Hortikultura. Buletin Penelitian Tanaman Hias Vol. 2 (2).

Reid, A. 2008. Greenhouse roses for cutflower production. Bulletin 4738. Department of Agriculture and Food. Western Australia. 8 pages.

Rukmana, R. 1994. Mawar. Penerbit Kanisius. Yogyakarta. 63 hal. 